\title{
Characterization of the wood combustion process based on the TG analysis, numerical modelling and measurements performed on the experimental stand
}

\author{
Mateusz Szubel1,a, Mariusz Filipowicz¹, Wojciech Goryl1 and Grzegorz Basista1 \\ ${ }^{1}$ AGH University of Science and Technology, Faculty of Energy and Fuels, A. Mickiewicza 30 Av., 30-059 Kraków, Poland
}

\begin{abstract}
The paper presents selected results of thermogravimetric (TG) analyses for softwood (pine) and hardwood (beech). The composition of the studied fuels has been defined and described. Both wood types used in the TG tests were studied in order to define their content of basic components such as lignin, cellulose and hemicellulose. Types of wood used in the TGA have been combusted on the experimental stand which is equipped with a set of temperature sensors and an exhaust analyser. A comparison of the TG analysis and the combustion in the heating unit has been performed to find relations between the kinetics of devolatilisation for different wood species and to determine the exhaust composition. Numerical modelling using computational fluid dynamics (CFD) has been performed for the process of carbon monoxide oxidation to supplement the tests results. The results of the comparisons of the performed analyses can be useful in all areas related to the process of optimisation and improvement of combustion, pyrolysis and devolatilisation process conditions in small scale heating units.
\end{abstract}

\section{Introduction}

Biomass, as an environment-friendly fuel, is gaining popularity. Local regulations often determine ranges of fuels which can be combusted in household heating devices. For this reason, utilization of wood in near future could rise rapidly.

Wood is the oldest form of biomass used for heat generation. Today, traditional fireplaces, furnaces and boilers have developed into advanced devices, equipped with expanded measurement instruments and control systems improving the efficiency of heat generation, but also producing a low emission of harmful combustion products [1].

A high quality of the device operation is possible if the details of the combustion process for each individual fuel are known, which allows to develop sets of operation recommendations, such as the process control algorithm, the appropriate load of the fuel, the position of the air nozzles in the combustion chamber, the construction materials etc. Changes of the air distribution in relation to the dynamics of temperature changes, but also to the current exhaust composition have to be taken into account.

Four fundamental stages of wood (and generally biomass) combustion need to be mentioned. The first phase includes the warming and drying of the fuel and there are no chemical reactions until the moment when the thermal decomposition starts (second stage). The moment of the beginning of this process depends on fuel properties, especially on the content of the major

\footnotetext{
a Corresponding author: mszubel@agh.edu.pl
}

components. Long drying related to a high moisture content in the fuel can lead to delayed ignition and it has impact on the composition of the volatiles. Products of solid fuel thermal decomposition are reduced and oxidized in a series of chemical reactions constituting the gasification process [2]. Gasification residues are coke and mineral substance (ash). The combustion of fixed carbon is the last stage of biomass combustion.

Gasification of wood can start in a relatively low temperature, about $220^{\circ} \mathrm{C}$, but different ingredients have different temperature of decomposition. The first important component, which undergoes gasification, is hemicellulose - in a temperature lower than $320^{\circ} \mathrm{C}$. Then decomposition of cellulose begins, between 320 and $370^{\circ} \mathrm{C}$. Lignin has the widest range of gasification temperature - between 320 and $500^{\circ} \mathrm{C}$ [3].

Effective combustion of wood is possible when the energy contained in the volatiles is efficiently converted to heat in the post-combustion process. The content of the total fuel calorific value which is contained in the volatiles could achieve even $70 \%$, making the gasification process the most significant stage of wood combustion, but also combustion of the other types of solid biomass, such as straw.

In the research of the process of combustion and the gasification process, both experimental and numerical methods are used. Tenorio and Moya [4] have performed TGA analyses to investigate the thermal stability of different fast-growth wood species planted in the tropics. They have also examined mass consumption during the burning process in order to identify different 
stages of the combustion process for these species. As a result of research, the most suitable species for the combustion process have been selected.

Garcia-Maraver et al. [5] have performed studies of the influence of different olive tree components on the combustion process of this type of biomass, using thermogravimetric analysis. As a result, a higher content of lignin in olive leaves has been identified as a factor responsible for the lower reaction rate of this component, which results in a higher ash content.

Vincente et al. [6] describe wood combustion experiments. The goal of study was to determine the effect of ignition technique, fuel load and cleavage as well as secondary air supply on carbon monoxide, total hydrocarbon, particulate matter (PM10) and particle number emissions from a wood stove. Pine wood and beech wood was selected to carry out the experimental tests.

According to Lamberg et al. [7], there is a significant difference in the particle emissions of samples collected from appliances representing different combustion situations in small-scale combustion. In the study described in the aforementioned paper, particle samples were collected from six appliances: five wood log fuelled stoves, including one stove equipped with modern combustion technology, three different conventional devices, one sauna stove and a modern pellet boiler. It was found that the combustion in the pellet boiler is the most efficient, which results in the smallest emissions, whereas inefficient batch combustion is always related to larger emissions (in this case, especially in the sauna stove).

Menghini et al. [8] have performed experimental and CFD analysis of a wood-open fireplace to determinate the possibility of the improvement of the total environmental impact of the device. A complete optimization cycle has been carried out and two configurations of heat exchanger were studied. It was established that it is difficult to improve combustion emission in domestic devices, where there is very little process control. However, significant improvements can be achieved as far as heat recovery efficiency. This can be done using suitable modifications of the heat exchanger.

\section{Materials and methods}

\subsection{Thermogravimetric analysis}

The thermogravimetric tests constituting a part of the research described in this paper were performed with use of TA Instruments SDT 2960 simultaneous TG - DTA apparatus. The device provides detection of the mass loss with a resolution of $0.1 \mu \mathrm{g}$. The measurement of temperature is performed inside the sample holder, situated in the furnace (Fig. 1). The furnace is a radiant chamber that creates a uniformly heated zone where a quartz reactor is located [9].

The remaining major parts of the aforementioned apparatus are: a PID controller, a gas feeding system with flowmeters, a data acquisition set and a precision balance [9].

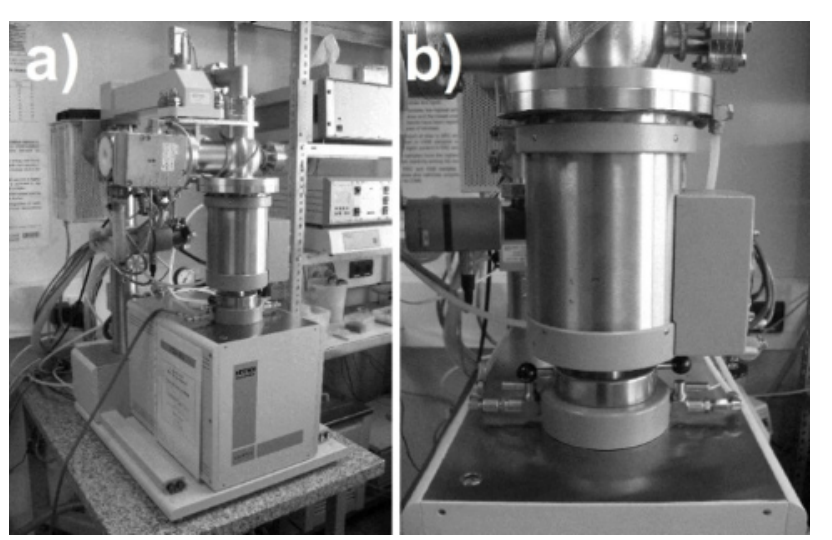

Figure 1. TA Instruments SDT 2960: a) general view, b) furnace.

The sample is exposed to thermal radiation by means of a stainless steel mesh screen the sides of which are wrapped on two stainless steel rods connected to a precision balance [9]. Inert gas flow, divided by two streams, connected with the furnace chamber and balance, establishes the proper reaction environment. An atmosphere of high purity nitrogen was used for the tests, at a flow rate of $1 \cdot 10^{-4} \mathrm{~m}^{3} / \mathrm{min}$.

An additional series of measurements has been carried out using an oxygen atmosphere, which was necessary to perform the fit of the mass loss curves for the samples and the curves designated using the mathematical model, which has been described in the subsequent part of the chapter.

The fuels (beech hardwood, pine softwood) used in the tests were prepared by drying and milling to a particle size of $<0.25 \mathrm{~mm}$. The accurate mass of the samples is presented in table 1 .

Table 1. Masses of samples used in tests

\begin{tabular}{|c|c|c|}
\hline No. of sample & Fuel & Mass [mg] \\
\hline H1 & Hardwood (beech) & 53.4 \\
\hline H2 & Hardwood (beech) & 53.4 \\
\hline S1 & Softwood (pine) & 53.5 \\
\hline S2 & Softwood (pine) & 53.5 \\
\hline
\end{tabular}

Each sample was heated with the heat rate $20 \mathrm{~K} \cdot \mathrm{min}^{-1}$ to $110^{\circ} \mathrm{C}$, then the temperature was maintained for 15 minutes (isothermal stage). Next, the sample was heated to $900^{\circ} \mathrm{C}$ (heat rate $20 \mathrm{~K} \cdot \mathrm{min}^{-1}$ ). The last stage of the process was cooling them down to about $30^{\circ} \mathrm{C}$.

To achieve accurate results, each sample was compared with the correction curve and a subtraction of both data series has been performed.

DTG curves always show partially overlapping peaks [10]. To separate the peaks related to the individual substances included in the samples, a mathematical model was used. It was assumed that three pseudo components are included in the samples (hemicellulose, cellulose and lignin). The mathematical model used in the calculations is based on an approximation of the individual reaction steps by reaction order of one. 
The equations are presented below:

$$
\frac{-d m}{d t}=\sum_{i=0}^{3} C_{i} \frac{d a_{i}}{d t}
$$

where:

$a$ - the volatile fractions released during devolatilisation $i$ - hemicellulose, cellulose, lignin

$C_{i}$ - contribution of the partial decomposition process $d a_{i} / d t$ - the mass loss rate for each component $t$ - time

$$
\frac{d a_{i}}{d t}=A_{i} \exp \left(\frac{-E_{i}}{R T}\right)\left(1-a_{i}\right)
$$

where:

$A_{i}$ - pre-exponential factor

$E_{i}-$ activation energy

$R$ - universal gas constant

$T$ - temperature

\subsection{Characterization of biomass combustion}

To describe the combustion behaviour of the analysed biomass, the double parallel reaction random pore model (DRPM) was applied [11]. According to this model, two competing reactions occur simultaneously:

$$
\begin{aligned}
& \text { wood_volatile }+\mathrm{O}_{2} \rightarrow \mathrm{H}_{2} \mathrm{O}+\mathrm{CO}_{2} \\
& \text { wood_residue }+\mathrm{O}_{2} \rightarrow \mathrm{CO}_{2}+\text { Ash }
\end{aligned}
$$

"wood_volatile" is considered as volatile matter in the sample and "wood_residue" is considered as carbon residue.

The DRPM model took into account the pore structure and its evolution during the reactions. According to the model, the pores of the particles are composed of randomly cylindrical pores of arbitrary size distribution, in which the reaction surface is given by the internal surface of the pores. It supposes that the reaction rate is proportional to its associated surface area. The combustion rate can be expressed as:

$$
\frac{d \alpha}{d T}=\frac{A}{\beta} \exp \left(\frac{-E}{R T}\right) \alpha \sqrt{1-\psi \ln \alpha}
$$

where $\alpha$ is non-converted fraction of the sample, $\beta$ - the heating rate in the non-isothermal thermogravimetric method, here equal to $20 \mathrm{~K} / \mathrm{min}, E$ - apparent activation energy and $\psi$ is a parameter of particle structure.

The $\psi$ parameter can be expressed as:

$$
\psi=\frac{4 \pi L_{0}\left(1-\varepsilon_{0}\right)}{S_{0}^{2}}
$$

where $S_{0}$ is the pore initial surface area, $L_{0}$ - the total pore length per unit volume $\left(\mathrm{m} / \mathrm{m}^{3}\right), \varepsilon_{0}-$ the solid porosity [12].

After the integration of eq. (5), the non-converted fraction can be expressed in the following form [11]:

$$
\alpha=\exp \left(-\operatorname{Aexp}\left(\frac{-E}{R T}\right)\left(\frac{T-T_{0}}{\beta}\right)\left(1+\frac{\operatorname{Aexp}\left(\frac{-E}{R T}\right)}{4 \psi}\left(\frac{T-T_{0}}{\beta}\right)\right)\right)
$$

where $T_{0}$ is the initial reaction temperature $(373 \mathrm{~K}$ in the present study).

The DRPM is expressed as a linear combination of the two competing processes (3) \& (4), each included by the appropriate fraction dependence $\alpha_{1}$ and $\alpha_{2}$.

So finally:

$$
\alpha=\varepsilon \alpha_{1}\left(A_{1}, E_{1}, \psi\right)+(1-\varepsilon) \alpha_{2}\left(A_{2}, E_{2}, \psi\right)
$$

To use this equation, it is necessary to determine six fitting parameters: $A_{1,2}, E_{1,2}, \psi$ and $\varepsilon$. The non-linear fitting procedure was applied to that end.

\subsection{Experimental analysis}

To compare results from the laboratory scale experiments (TGA) and mathematical calculations (DRPM) with the experimental data, a measurement stand based on an accumulation fireplace, equipped with temperature sensors and an exhaust analyser (Fig. 2), as well as a control damper of the chimney draft has been applied (Fig. 3)

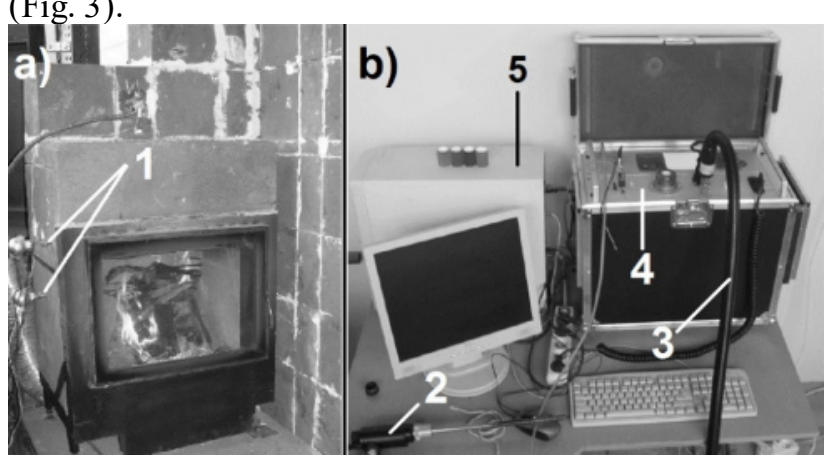

Figure 2. Experimental stand: a) general view of the accumulation stove with visible temperature sensors (1); b) main elements of the exhaust analysis system, including the probe (2), the gas duct (3), the measuring system (4) and the computer (5).

In case of the heating unit applied in the experimental works, ceramic accumulation material has been used to optimize the current power of the device and reduce the concentration of undesirable components of exhaust (mainly carbon monoxide). Details of the design and the operation of the accumulation stoves - fireplaces are described in [13].

For both pine and beech slivers of wood, two experiments have been performed. In view of the fact that during the measurement it was not possible to combust samples of wood mass in milligrams as it took place in the TG analysis, the mass of wood for hard and soft wood was $5.4 \mathrm{~kg}$. The wood that was combusted in the fireplace was the same as in the TG analysis, but in form of slivers. Before each measurement series, pre-combustion has been carried out to warm up the combustion chamber. In both cases, the humidity of fuel was approximately $12-15 \%$. The fuel load was $5.4 \mathrm{~kg}$ in each experiment. Each type of wood was combusted two times. The time of the measurement was about 
55 minutes. Due to the recommendations of the device producer, the control damper of the chimney draft was set on the $-12 \mathrm{~Pa}$.

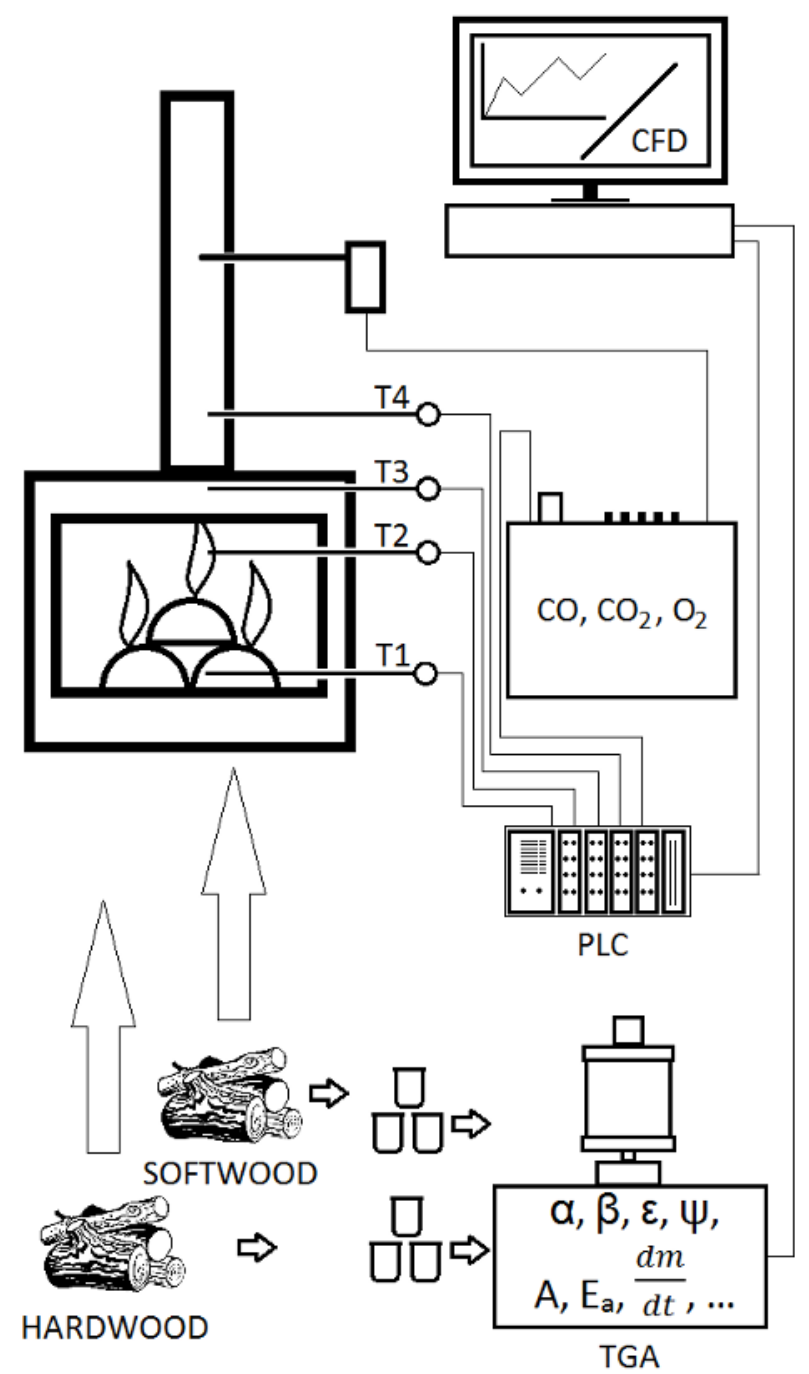

Figure 3. Schematic diagram of the experimental stand.

The air for the combustion process is provided by two parallel gaps located on the bottom and top of the front frame of the hearth. The charging of the air for both supplying degrees is realised through one pipe $(150 \mathrm{~mm}$ diameter), installed under the body of the hearth.

During the experimental measurements, type $\mathrm{K}$ thermocouples were used. In Figs. 6 and 7 they are listed as T1, T2, T3 and T4 and were situated in the combustion chamber, above the deflector, above the smoke conduit and in the chimney, respectively. Moreover, the WAGO System has been used to connect thermocouples to the computer where the data was collected.

The MRU ECO 3000 exhaust analyser has been applied in the studies.

\subsection{Numerical analysis}

To analyse the distribution of gases and the reaction process inside the combustion chamber of the ceramic hearth, the CFD method has been applied. Spatial geometry of the hearth has been developed using the CAD tool and exported to the ANSYS Workbench
15. Then DesignModeler has been employed to define the computational domain of the combustion chamber interior (Fig. 4).

ANSYS Meshing has been applied for the domain discretisation. As a result of this process, $5 \cdot 10^{5}$ of the mesh elements were generated. Multizone method has been used to create mesh in most regions of the domain.

A set of significant process and device operation parameters has been defined as boundary conditions. Domain reference pressure was $101325 \mathrm{~Pa}$. Inlet was defined as an opening boundary with relative pressure of $0 \mathrm{~Pa}$ and air temperature of $283.15 \mathrm{~K}$. The outlet relative pressure, according to the experiment, was set as $-12 \mathrm{~Pa}$. The outlet opening temperature (after the outlet from the computational domain) was defined based on the average temperature on the outlet surface. The glass contact surface and the walls contact surfaces were characterised by heat transfer coefficients of $145 \mathrm{~W} /\left(\mathrm{m}^{2} \mathrm{~K}\right)$ and $110 \mathrm{~W} /\left(\mathrm{m}^{2} \mathrm{~K}\right)$ respectively. Based on the measurement carried out during the experimental tests, the assumed ambient temperature was $283.15 \mathrm{~K}$.

The K-epsilon model of turbulence has been applied due to the lack of the near-wall layer analysis.

The goal of the study was to investigate the distribution of fuel decomposition products and the areas of efficient combustion, as well as the impact of the locations of air inlets. Gasification products have been limited to $\mathrm{CO}$ and $\mathrm{H}_{2} \mathrm{O}$. Top surfaces of the wood slivers have been defined as the volatiles inlet. The mixture composition as well as temperature of the gas fuel have been determined based on the DG and experimental tests.

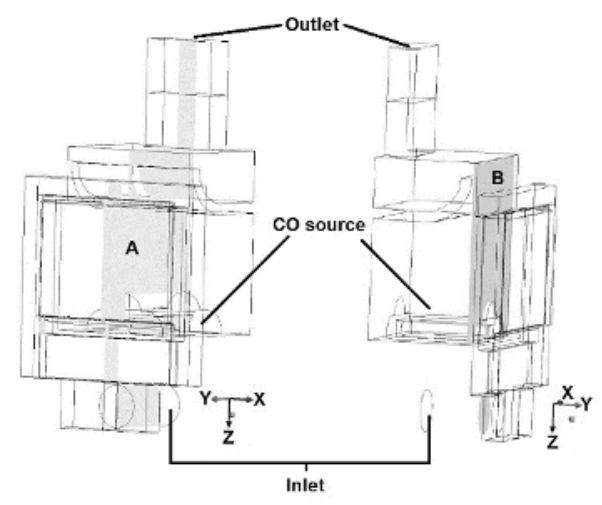

Figure 4. Computational domain of the combustion chamber, designed based on the experimental stand with marked inlet, outlet and $\mathrm{CO}$ source. The cross sections used in the presentation of the results are marked as "A" and "B" (on two different views of the domain).

Finite rate chemistry and the eddy dissipation model of combustion with the Arrhenius equation has been applied. Discrete transfer model of radiation with "surface to surface" mode has been used, including multigray mode of the mixture components properties.

\section{Results and discussion}

To perform an evaluation of the kinetic parameters concerning the thermal decomposition process and a determination of the fractions of components 
for hard and soft wood (table 1) (regarding thermal devolatilisation behaviour), dedicated software based on Matlab was employed. To define specific temperature points of thermogravimetric curves, first derivative of mass loss in samples has been calculated (Fig. 5). The curves in Fig. 3 present an average value from two samples H1, H2 and S1, S2 for hard and soft wood, respectively. Then, specific temperature points at the curves were defined (points of the curve trend changes especially peaks, onsets/offsets, inflections etc.).

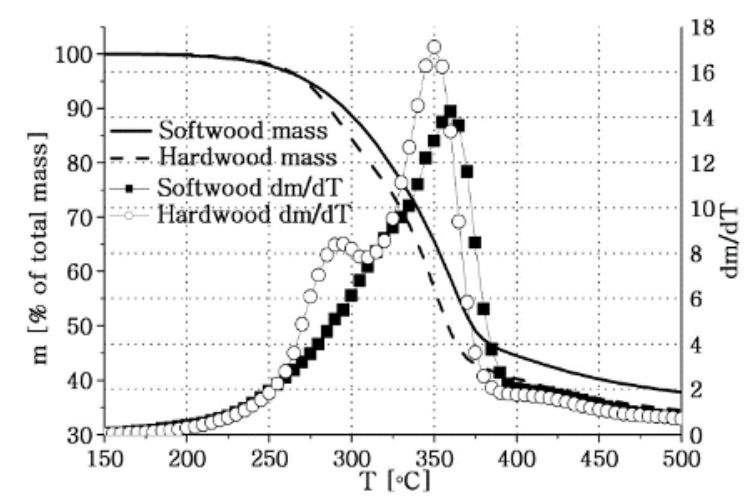

Figure 5. Thermogravimetric curves and first derivatives of mass loss for the considered wood species.


Figure 6. DTG for: a) hardwood, b) softwood.

The shoulders and tailings on the DTG curves of fuels (Fig. 6) indicate that the analysed biomass consist of components characterized by different pyrolysis reactivity. As in Fig. 5, curves in Fig. 6 present an average value from two samples $\mathrm{H} 1, \mathrm{H} 2$ and $\mathrm{S} 1, \mathrm{~S} 2$ for hard and soft wood, respectively.

For hardwood, the point which can be understood as a beginning of hemicellulose decomposition was found for the temperature value of about $210^{\circ} \mathrm{C}$. Because of the specifics of beech wood pyrolysis in the $250^{\circ} \mathrm{C}-300^{\circ} \mathrm{C}$ temperature range, a second characteristic point of the process was found as a first peak on the $d m / d T$ curve in Fig. 5. The point is related to the temperature of the maximum hemicellulose decomposition rate, which in this case was equal to about $6.3 \%$ of dry mass per minute in the temperature of $275^{\circ} \mathrm{C}$. The second peak in the top region of the chart can be understood as the temperature of the maximum cellulose decomposition rate, equalling to about $15.4 \%$ per minute. The temperature for this point is $350^{\circ} \mathrm{C}$. For hardwood, the average temperature of the end of cellulose decomposition point is equal to about $475^{\circ} \mathrm{C}$. The moment when the curve in Fig. 5 representing mass loss returns to horizontal is related to the achievement of solid residue of sample (charcoal). In case of beech wood, it is about $35 \%$ of the initial sample mass.

Different decomposition characteristics were obtained as a result of the measurement of pine wood samples. First, the lower peak identified in case of beech wood is not present in this case. The temperature of the beginning of hemicellulose decomposition is higher than for beech samples, equalling to about $220^{\circ} \mathrm{C}$. It is difficult to define the maximum hemicellulose decomposition rate because of the insignificant curve angle change in the range between $250^{\circ} \mathrm{C}$ and $360^{\circ} \mathrm{C}$. This parameter has been established using simulation fit as a point of the curve inflection, in the temperature of $315^{\circ} \mathrm{C}$, which was higher than for beech wood (about $40^{\circ} \mathrm{C}$ ). A smaller difference between pine and beech wood has been observed for the temperature of the maximum cellulose decomposition rate - about $360^{\circ} \mathrm{C}$.

Temperature values, decomposition rates and activation energy of decomposition of the considered pseudo components for beech and pine wood samples are included in table 2 . Table 2 presents the average value of sample H1, H2 and S1, S2 for hard and soft wood, respectively. The point of maximum decomposition rate for lignin in comparison to beech samples is moved to the left. For pine wood, it is between $360^{\circ} \mathrm{C}$ and $370^{\circ} \mathrm{C}$, whereas in case of hardwood it is about $400^{\circ} \mathrm{C}$.

Some information related to fixed carbon (charcoal fraction) was obtained using the DRPM model. These results can be applied to the analysis of the last stage of biomass combustion, an aforementioned stage of fixed carbon combustion. The content of fixed carbon and its temperature dependence is important at the end of wood combustion in fireplaces.

The obtained results for two types of wood (hard and soft wood) using DRPM (eq. 7) are presented in Fig 7. The solid curves show results of the fitting procedure of the fractional conversion of the biomass samples. 
Table 2. Results of the calculations concerning the content and decomposition rates of the pseudo components included in the wood samples

\begin{tabular}{|c|c|c|c|c|c|c|c|c|c|c|c|}
\hline \multirow{3}{*}{ No. } & \multirow{3}{*}{ Fuel } & \multirow{3}{*}{ Component } & \multicolumn{6}{|c|}{$T G A$} & \multicolumn{3}{|c|}{$\overline{D R P M}$} \\
\hline & & & $\begin{array}{l}\text { Mass } \\
\text { fraction }\end{array}$ & $\begin{array}{l}\text { Dec. } \\
\text { start }\end{array}$ & $\begin{array}{l}\text { Dec. } \\
\text { end }\end{array}$ & {$[-d m / d t]_{\max }$} & $E a$ & $\ln (A)$ & $E_{1}$ & $E_{2}$ & $\psi$ \\
\hline & & & $\begin{array}{c}\text { [wt } \% \\
\text { d.b.] }\end{array}$ & {$\left[{ }^{\circ} \mathrm{C}\right]$} & {$\left[{ }^{\circ} \mathrm{C}\right]$} & {$[\mathrm{wt} \% / \mathrm{min}]$} & $\begin{array}{l}{[\mathrm{kJ} /} \\
\mathrm{mol}]\end{array}$ & {$\left[\mathrm{s}^{-1}\right]$} & $\begin{array}{l}{[\mathrm{kJ} /} \\
\mathrm{mol}]\end{array}$ & $\begin{array}{l}{[\mathrm{kJ} /} \\
\mathrm{mol}]\end{array}$ & \\
\hline \multirow{3}{*}{1.} & \multirow{3}{*}{ Hardwood } & Hemicellulose & 16.7 & 210 & 337 & 6.3 & 123.3 & 22.4 & \multirow{3}{*}{92.8} & \multirow{3}{*}{2.9} & \multirow{3}{*}{2.2} \\
\hline & & Cellulose & 33.5 & 267 & 383 & 15.4 & 191.2 & 33 & & & \\
\hline & & Lignin & 15.3 & $<200$ & $>500$ & 1.7 & 44.5 & 2.6 & & & \\
\hline \multirow{3}{*}{2.} & \multirow{3}{*}{ Softwood } & Hemicellulose & 14.2 & 220 & 366 & 4.4 & 112 & 19.9 & \multirow{3}{*}{88.5} & \multirow{3}{*}{0.5} & \multirow{3}{*}{9.2} \\
\hline & & Cellulose & 26.7 & 276 & 395 & 12 & 193.8 & 34.2 & & & \\
\hline & & Lignin & 21.3 & $<150$ & $>500$ & 2.1 & 31.3 & 0.4 & & & \\
\hline
\end{tabular}



Figure 7. Fractional conversion data fitted by DRPM model for hard and soft wood.

Better fitting results were obtained for hardwood. It is visible that the charcoal fraction in the samples is much higher for softwood as compared to hardwood. In both cases the combustion of fixed carbon starts in a temperature a little higher than $600 \mathrm{~K}$.

According to eq. 8 , the first activation energy $E_{1}$ is similar in both cases and equal to $92.8 \mathrm{~kJ} /(\mathrm{mol})$ for hardwood and $88.5 \mathrm{~kJ} /(\mathrm{mol})$ for softwood and the second activation energy $E_{2}$ is 2.9 and 0.5 , respectively. The parameter of the particle structure $\psi$ is equal to 2.2 for hardwood and 9.2 for softwood (see Table 2).

Fig. 8 shows the variation of temperature and $\mathrm{CO}$ emission during hardwood combustion in the fireplace. Two combustions of beech wood were performed and in Fig. 8 the average temperature and $\mathrm{CO}$ emission is presented. First, a rapid increase of temperature caused by intensive burning of volatiles is observed from the $3^{\text {rd }}$ - $4^{\text {th }}$ minute of measurements. Then, after about 15 minutes, the temperature in combustion chamber becomes relatively stable. Next, there is a rapid drop of temperature until the end of the combustion process. The emission of $\mathrm{CO}$ during beech wood combustion in the fireplace is relatively low until approximately 25 $\mathrm{min}$. Then the emission increases rapidly up to $8000-$ $10000 \mathrm{ppm}$, where the value is stabilized.



Figure 8. Average temperature and $\mathrm{CO}$ emission $(13 \% \mathrm{O} 2)$ changes in time during hardwood combustion in the fireplace.



Figure 9. Average temperature and $\mathrm{CO}$ emission $(13 \% \mathrm{O} 2)$ changes in time during softwood combustion in the fireplace.

The curves shown in Fig. 9 present the changes of temperature and $\mathrm{CO}$ emission during pine wood combustion. Two combustions of pine wood were performed and in Fig. 9 the average temperature and $\mathrm{CO}$ emission is presented. Burning softwood is characterized by significantly different waveforms of temperature and $\mathrm{CO}$ emission. Pine wood, as compared to beech wood, reached much higher temperatures in the combustion chamber, which were caused by a higher resin content in the wood. The period of stable temperature, after the initial increase at the beginning of the burning, is shorter by 5 minutes. After 15 minutes from the start of the combustion process, the temperatures start to slowly fall

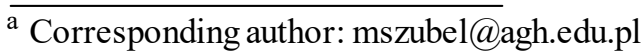


down to reach about $300^{\circ} \mathrm{C}$. The curve showing $\mathrm{CO}$ emission is characterized by a sharp peak at approx. 5 min of combustion process. Mostly, it is caused by the high resin content of pine wood and its higher lignin content, which start to decompose in lower temperature as compared to beech wood.

The comparison of Figs. 8 and 9 shows that in the last stage of the process related to fixed carbon combustion, the higher temperature was obtained for softwood ca. $300^{\circ} \mathrm{C}$ as compared to ca. $250^{\circ} \mathrm{C}$ for hardwood, and the rate of the temperature decrease is a little slower for softwood. It is related to the results presented in Fig. 7 , where the higher content of fixed carbon for softwood is visible ( $45 \%$ vs. $35 \%$ ). Moreover, the charcoal fraction from the softwood samples is burning a little slower.

a)



b)

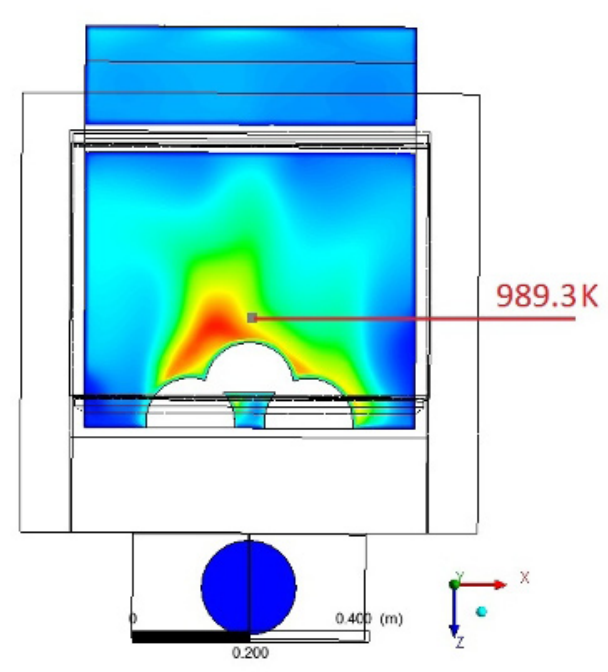

Figure 10. Temperature in the combustion chamber for: a) hardwood, b) softwood.

Figures 10 and 11 present selected results of the evaluated CFD modelling of the heating device. The simulations has been carried out to analyse spatial distribution of some exhaust components, and consequently to investigate impact of current design of the air distribution system on the process of the fuel combustion. Obtained results confirm, that impact of construction of the combustion chamber, including air staging system configuration is from the combustion process point of view equally important as the fuel properties. To show clearly impact of the gas streams (combustion air, gaseous fuel, reaction products) in the combustion chamber on the characteristics of the oxidation of the volatiles represented mainly by the $\mathrm{CO}$, front view as well as side view of the combustion area are presented.

Observed different temperature levels and $\mathrm{CO}_{2}$ concentration for soft and hard wood confirms effect of pseudocomponets composition decomposition rate. As mentioned in previous chapters, thermal decomposition of the pseudocomponents of the biomass fuel is strongly temperature-dependnd. Due to the fact, that in terms of the high temperature liquid products of the lignin destruction are secondary-converted to simple molecules such as $\mathrm{CO}$, intensified phenomena of $\mathrm{CO}$ production can be noted in case of the fuel characterised by higher content of the lignin (softwood).



b)

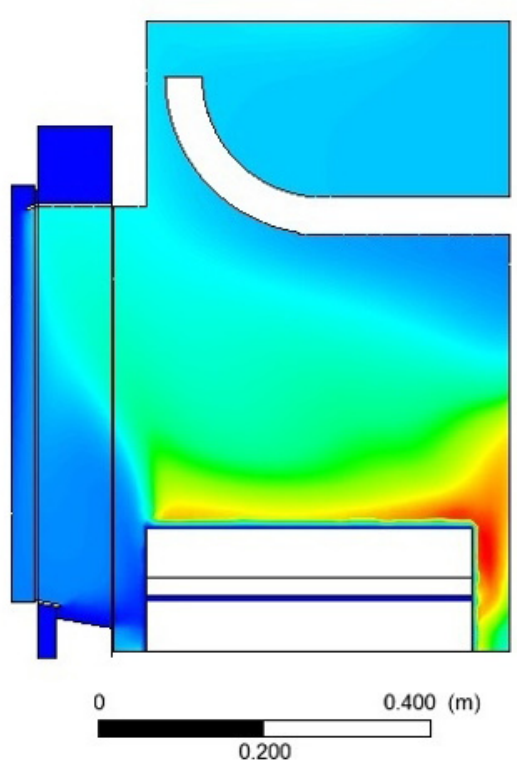

Figure 11. $\mathrm{CO}_{2}$ mass fraction for: a) hardwood, b) softwood. 
Despite the difference in range of the temperature level, profile of the flame is similar in both cases. It proves that significant factor which determines flame propagation is distribution of the gas streams in the combustion chamber. Air staging is achieved by the system of the channels situated in front housing of the glass door. First part of the combustion air flows from the bottom (below door, just above the bottom of the combustion chamber) through the fuel bed, to the rear wall of the chamber. Second part of the air is released from the slot above the door and it is distributed on the glass, mainly to avoid soot (see red arrows on Fig. 11 a): 1 - first part of the air, 2 - second part of the air). As a result of this approach to air feeding process, it is visible, that temperature level and the $\mathrm{CO}_{2}$ concentration is much lower in regions in which free flow of the air is possible (near to glass and walls, as well as in the left and right part of the bottom of the combustion chamber). Moreover, due to different hydraulic resistance for streams 1 and 2, mass flow rate in the both inlets is different and not homogenous along the slots. In analysed cases, it causes deflection of the flame region to the left wall (Fig. 10).

Products of gasification are transported from the areas of syngas by relatively cool air released from the inlet slots and after heating, reactions can occur in rear part of the combustion chamber (Fig. 11). Inhomogenous temperature distribution related with the phenomena mentioned above can influence on the efficiency of the combustion of the gasification products. In case of the $\mathrm{CO}$ oxidation, presence of some radicals (i.eg. - $\mathrm{OH}$ ) is equally important that presence of oxygen or high temperature [14]. Due to this fact, different rate of the stages of combustion in different areas of the chamber can disturb combustion process and increase concentration of $\mathrm{CO}$ in exhaust. This efect is partially responsible for the high $\mathrm{CO}$ emmision at the begining of each experimental test presented previously.

\section{Conclusions}

Two types of wood were compared as fuel in fireplaces. The first analysis was devoted to the detailed study of its decomposition using small samples of fuel, then the combustion of the appropriate fuel was performed in the fireplace. Results obtained during the laboratory analysis can be applied to the analysis of fuel combustion in the fireplace. Especially the different contents of three main components, ie. hemicellulose, cellulose, and lignin determine the ignition rate, the temperature growth rate and the maximal temperature. The fixed carbon contents determine the temperature decrease in last stage of the process. It has been demonstrated that all these parameters can be applied in CFD modelling of biomass combustion.

\section{References}

1. W. Rybak, Spalanie i wspótspalanie biopaliw statych Combustion and co-combustion of solid biofuels. (Oficyna wydawnicza Politechniki Wrocławskiej, Wrocław, 2006)
2. B. Sørensen, Renewable energy. Its physics, engineering, environmental impacts, economics \& planning (Academic Press, London, 2000)

3. W. Kordylewski, Spalanie i Paliwa Combustion and Fuels. (Oficyna wydawnicza Politechniki Wrocławskiej, Wrocław, 2008)

4. C. Tenorio, R. Moya 2013.. Thermochim. Acta 563, 12-21 (2013)

5. A. Garcia-Maraver, D. Salvachua, M.J. Martinez, L.F. Diaz, M. Zamorano, Waste Manage., 33, 11 (2013)

6. E.D. Vincente, M.A. Duarte, A.I. Calvo, T.F. Nunes, L. Tarelho, C.A. Alves, Fuel Process. Technol, 131, 182-192 (2015)

7. H. Lamberg, K. Nuutinen, J. Tissari, J. Ruusunen, P. Yli-Pirila, O. Sippula, M. Tapanainen, P. Jalava, U. Makkonen, K. Teinila, K. Saarnio, R. Hillamo, M.-R. Hirvonen, Jokiniemi, Atmos. Environ., 45, 7635 $7643(2011)$

8. D. Menghini, T. Marchione, G. Martino, S.F. Marra, Ch. Allouis, F. Beretta, Exp. Therm. Fluid Sci., 21, 477-482 (2007)

9. G.M. Ronli, G. Varhegyi, C. Di Balsi, Ind. Eng. Chem. Res., 41, 4201-4208 (2002)

10. C. Branca, C. Di Barsa, Energ. Fuel., 17, 1609-1615 (2003)

11. G. Wang, J. Zhang, J. Shao, S. Ren, Thermochim. Acta, 591, 68-74 (2014)

12. H. Fei, L. Sun, S. Hu, J. Xiang, Y. Song, B. Wang, G . Chen, J. Anal. Appl. Pyrol., 91, 251-256 (2014)

13. L. Kurcz, M. Filipowicz, K. Sornek, M. Szubel, K. Rzepka, J. Ręka, Ciepłownictwo Ogrzewnictwo Wentylacja, 46, 104-111 (2015)

14. S. van Loo, J. Coppejan, The handbook of biomass combustion and co-firing (EARTHSCAN, London 2008)

\section{Acknowledgements}

The thermogravimetric analysis was carried out within the "Biofuels Research Infrastructure for Sharing Knowledge" project in Bioenergy 2020+ company (Graz, Austria). The studies performed on the experimental stand and the CFD analyses were carried out under contract (11.11.210.217), AGH-University of Science and Technology, Faculty of Fuels and Energy, Cracow, Poland.

The construction of the measurement stand with the accumulation stove was possible thanks to the CEBUD company (Krakow, Poland). 